\title{
Development of a resonant-type microwave reactor and its application to the synthesis of positron emission tomography radiopharmaceuticals.
}

\section{$\operatorname{AUTHOR}(S)$ :}

Kimura, Hiroyuki; Yagi, Yusuke; Ohneda, Noriyuki; Odajima, Hiro; Ono, Masahiro; Saji, Hideo

\section{CITATION:}

Kimura, Hiroyuki ... [et al]. Development of a resonant-type microwave reactor and its application to the synthesis of positron emission tomography radiopharmaceuticals.. Journal of labelled compounds \& radiopharmaceuticals 2014, 57(12): 680-686

\section{ISSUE DATE:}

2014-08-08

URL:

http://hdl.handle.net/2433/198616

\section{RIGHT:}

This is the peer reviewed version of the following article: Kimura H., Yagi Y., Ohneda N., Odajima H., Ono M., and Saji H. (2014), Development of a resonant-type microwave reactor and its application to the synthesis of positron emission to mography radiopharmaceuticals, J. Label Compd. Radiopharm, 57, pages 680-686, which has been published in final form at http://dx.doi.org/10.1002/jlcr.3232.; 許諾条件により本文ファイルは2015-08-08に公開.; この論文は出版社版で ありません。引用の際には出版社版をご確認じ利用ください。;This is not the published version. Please cite only the published version. 


\title{
Development of a resonant-type microwave reactor and its application to the synthesis of PET radiopharmaceuticals
}

\author{
Hiroyuki Kimura1,2,*\#, Yusuke Yagi ${ }^{1 \#}$, Noriyuki Ohneda ${ }^{3}$, Hiro Odajima ${ }^{3}$, \\ Masahiro Ono ${ }^{1}$, and Hideo Saji ${ }^{1, *}$
}

${ }^{1}$ Department of Patho-Functional Bioanalysis, Graduate School of Pharmaceutical Sciences, Kyoto University, 46-29 Yoshida Shimoadachi-cho, Sakyo-ku, Kyoto 606-8501, Japan

${ }^{2}$ Radioisotope Research Center of Kyoto University, Yoshida Konoe-cho, Sakyo-ku, Kyoto 606-8501, Japan

${ }^{3}$ Technology Development Dept., SAIDA FDS Inc., 143-10 Isshiki, Yaizu, Shizuoka 425-0054, Japan 
*To whom correspondence should be addressed:

Tel: +81-75-753-4566

Fax: +81-75-753-4568

E-mail: hsaji@pharm.kyoto-u.ac.jp

hkimura@pharm.kyoto-u.ac.jp

\#These authors contributed equally to this work 


\section{Abstract}

Microwave technology has been successfully applied to enhance the effectiveness of radiolabeling reactions. The use of a microwave as a source of heat energy can allow chemical reactions to proceed over much shorter reaction times and in higher yields than they would do under conventional thermal conditions. A microwave reactor developed by Resonance Instrument Inc. (Model 520/521) and CEM (PETWave) has been used exclusively for the synthesis of radiolabelled agents for positron emission tomography (PET) by numerous groups throughout the world. In this study, we have developed a novel resonant-type microwave reactor powered by a solid-state device, and confirmed that this system can focus microwave power on a small amount of reaction solution. Furthermore, we have demonstrated the rapid and facile radiosynthesis of $\quad 16 \alpha-\left[{ }^{18} \mathrm{~F}\right]$ fluoroestradiol $\quad\left(\left[{ }^{18} \mathrm{~F}\right] \mathrm{FES}\right)$, 4-[ $\left[{ }^{18}\right.$ F]fluoro- $N$-[2-(1-methoxyphenyl)-1-piperazinyl]ethyl- $N$-2-pyridinylbenzamide $\left(\left[{ }^{18} \mathrm{~F}\right] \mathrm{MPPF}\right)$ and $N$-succinimidyl $4-\left[{ }^{18} \mathrm{~F}\right]$ fluorobenzoate $\left(\left[{ }^{18} \mathrm{~F}\right] \mathrm{SFB}\right)$ using our newly developed microwave reactor.

Keywords: resonant-type microwave reactor, positron emission tomography radiochemistry, ${ }^{18} \mathrm{~F}$-fluorination, $\left[{ }^{18} \mathrm{~F}\right] \mathrm{FES},\left[{ }^{18} \mathrm{~F}\right] \mathrm{MPPF},\left[{ }^{18} \mathrm{~F}\right] \mathrm{SFB}$ 


\section{Introduction}

Since Gebye and Giguere reported microwave synthesis in a sealed tube with a domestic microwave oven in 1986, there has been rapid increase in research efforts directed towards the study of organic reactions in a microwave ${ }^{[1,2]}$.

Based on the significance of this early work, numerous microwave reactors have been developed and optimized for synthetic applications, where it is possible to control the temperature and pressure of the reaction mixture inside the reactor. Many researchers have reported that the use of a microwave as a source of heat energy can enable reactions to proceed over much shorter reactions times and in higher yields than they would do under conventional thermal conditions ${ }^{[3-8]}$. Compounds labeled with ${ }^{18} \mathrm{~F}$ are used as positron emission tomography (PET) tracers. The introduction of ${ }^{18} \mathrm{~F}$ atoms into an organic compound (i.e., ${ }^{18}$ F-fluorination reactions), however, invariably requires high temperatures and long reaction times because fluoride anions are only weakly nucleophilic. Furthermore, the use of long reaction times for the introduction of ${ }^{18} \mathrm{~F}$ atoms can be problematic because the half-life of ${ }^{18} \mathrm{~F}(109.7 \mathrm{~min})$ is very short. A microwave-based ${ }^{18} \mathrm{~F}$ labeling method was recently reported, and has drawn considerable attention from researchers working in a variety of different fields because this new microwave-assisted method improved yields, reduced the generation of side 
products and shortened reaction times compared with conventional heating methods such as oil baths and hotplates ${ }^{[9-13]}$. A microwave reactor developed by Resonance Instrument Inc. (Model 520/521) and CEM (PETWave) has been used exclusively for the synthesis of radiolabelled agents for PET by numerous groups throughout the world.

Commercial microwave reactors use a magnetron as an oscillator, which can struggle to irradiate small areas of a reaction mixture (such as those found in PET radiochemistry) with appropriate levels of power, and it can therefore be difficult for these systems to achieve sufficient microwave heating ${ }^{[14,15]}$. In this study, we have developed a novel resonant-type microwave reactor that is powered by a solid-state device. Notably, the frequency of the solid-state oscillator in this system can be tuned to efficiently heat a small amount of solution in the resonant cavity, and provide excellent heating to the reaction mixture to allow for the synthesis of PET radiopharmaceuticals.

\section{Results and discussion}

Figure 1 shows a picture of the microwave reactor system developed in this study, including the resonant cavity and reaction vessel. The key features of this system are as follows: (1) a solid-state microwave device, which was originally developed for use in cellular phone systems (instead of a magnetron source); (2) a resonant cavity 
operating in a TM010 single-mode ${ }^{[16]}$; and (3) a high speed feedback system for tuning the frequency and controlling the power. The oscillation unit consists of a voltage controlled oscillator (VCO), variable attenuator (VAT), high power amplifier (HPA), and programmable logic controller (PLC). Microwave power (50 W max) from the oscillation unit was transmitted to the irradiation unit via a coax cable. This newly developed microwave reactor can be placed in small spaces such as a hot cell because the resonant cavity is separated from the oscillation unit.

\section{Figure 1}

Figure 2 shows the structure of the irradiation unit. The coupling of the microwave power to the resonant cavity was made possible by placing an antenna in the cavity. The cavity has two openings; one for installing a vial and another for monitoring the temperature using an infrared (IR) thermometer. The IR thermometer placed outside of the cavity was used to monitor the temperature of the vial. By maintaining the resonant conditions at a consistent level, it was possible to reduce the leakage of any microwave power from the cavity to a negligible level. Furthermore, this newly developed microwave reactor operates in the industrial, scientific and medical 
frequency band of 2.4-2.5 GHz. It is difficult to calculate the electromagnetic field of a region heated with a domestic microwave oven with a multi-mode cavity. In contrast, the electromagnetic field of the resonance cavity can be calculated precisely for any object placed at the highest energy point in our newly developed microwave reactor. This newly developed microwave reactor can therefore provide effective heating whilst using minimum electrical power. The dielectric properties of a reaction system can change depending on the type of reagents used and the temperature of the system. For this reason, the oscillator frequency needs to be repeatedly tuned to the cavity resonance during the operation. To address this issue, we equipped our newly developed microwave reactor with a feedback control consisting of an electric field and frequency-variable solid-state oscillator $(2.4-2.5 \mathrm{GHz})$. In this way, the operator can select either a constant microwave power mode or a temperature control mode, where the microwave power is automatically adjusted by VAT based on the temperature measured by the IR thermometer. The operator can then enter the conditions for their synthesis, including the microwave power, irradiation time and temperature of the reagent, through a PC interface. Our newly developed microwave reactor was also equipped a real-time monitoring system, which allowed for several variables to be monitored simultaneously, including (1) the resonance frequency, (2) electric field in the 
cavity, (3) input power, (4) reflection power, and (5) temperature. The control unit was designed to perform various safety functions, such as instigating an automatic shutdown procedure if the temperature exceeded a preset limit to ensure safer operation.

\section{Figure 2}

Figure 3 shows a simulation of the electrical field distribution in the cavity together with a reagent in a borosilicate vial. It is can be seen from the figure that this newly developed microwave reactor can effectively irradiate a small amount of solvent and provide efficient heating through the direct coupling of microwave energy with the molecules that are present in the reaction mixture. This reactor system could therefore be used to rapidly and effectively heat a small amount of reaction mixture such as the solutions required for the synthesis of PET radiopharmaceuticals.

\section{Figure 3}

To evaluate the heating efficiency of our new system, we measured the heating rate $\left({ }^{\circ} \mathrm{C} / \mathrm{s}\right)$ of several high-dielectric loss solvents, including acetonitrile (MeCN), 
dimethylformamide (DMF), dimethyl sulfoxide (DMSO) and methanol (MeOH). Several low-dielectric loss solvents were also investigated, including toluene and tetrahydrofuran (THF) (Table 1). The reaction vessel was irradiated with microwave irradiation at $50 \mathrm{~W}$ (maximum power). The time taken to reach $60{ }^{\circ} \mathrm{C}, 80{ }^{\circ} \mathrm{C}$ and the boiling point of each solvent was recorded. Because DMSO has a very high boiling point, the third temperature was taken as the maximum temperature of the microwave reactor (i.e., $180{ }^{\circ} \mathrm{C}$ ) instead of the boiling point.

The experiment revealed that the polar aprotic solvent $\mathrm{MeOH}$ possessed the fastest heating rate. For DMF and DMSO, which have high boiling points, the microwave reactor could efficiently heat these solvents at high temperatures. MeCN, which is frequently used as a solvent in PET radiosynthesis, could be heated efficiently without a significant decrease in the heating rate, even at its boiling point. It is noteworthy that a reduction in the solvent volume $(0.05-0.2 \mathrm{~mL})$ had very little impact on the rate of heating. It is important to reduce the amount of solvent used in PET chemistry, and our newly developed system made it possible to run a reaction using a high concentration of precursor. In contrast, toluene and THF, which are both low-dielectric loss solvents, had low heating rates. This suggests that the choice of the rate of the temperature increase, should be variable to account for the solvent effects. 


\section{Table 1.}

To demonstrate the effectiveness of our newly developed microwave reactor

through the evaluation of the heating effect, we carried out the radiosynthesis of several known PET tracer compounds.

$16 \alpha-\left[{ }^{18} \mathrm{~F}\right]$ Fluoroestradiol $\left(\left[{ }^{18} \mathrm{~F}\right] \mathrm{FES}\right)$ was selected as a model compound to

investigate the ${ }^{18} \mathrm{~F}$-fluorination for the sulfonate group ${ }^{[17,18]}$ (Table 2). $\left[{ }^{18} \mathrm{~F}\right] \mathrm{FES}$ is an estradiol derivative with the highest bioactivity of all of the known estrogens, and this compound be useful for the diagnosis of estrogen-dependent diseases and the evaluation of the effectiveness of hormone therapy. Under conventional heating conditions, the synthesis of $\left[{ }^{18} \mathrm{~F}\right] \mathrm{FES}$ required $10 \mathrm{~min}$ of fluorination with $\left[{ }^{18} \mathrm{~F}\right] \mathrm{KF}$ in the presence of Kryptofix2.2.2 and $\mathrm{K}_{2} \mathrm{CO}_{3}$, followed by a 10 min deprotection step with an aqueous solution of hydrochloric acid (Table 2, entry 1). When the reaction time was shortened under conventional heating conditions, it was not possible to achieve the desired level of ${ }^{18} \mathrm{~F}$-fluorination because the ${ }^{18} \mathrm{~F}$-fluorination yield was low and the deprotection reaction did not proceed (Table 2, entry 2). In contrast, microwave heating gave a better yield of $\left[{ }^{18} \mathrm{~F}\right] \mathrm{FES}$, with each reaction requiring only $1 \mathrm{~min}$ (Table 2, entry 3). Furthermore, the yield of $\left[{ }^{18} \mathrm{~F}\right] \mathrm{FES}$ remained unchanged until the concentration of the 
amount of the precursor was decreased by $75 \%$ (Table 2, entries 4 , 5). This indicates that it is possible to reduce the amount of precursor used in the synthesis of PET tracers using our newly developed microwave reactor.

\section{Table 2}

The

nucleophilic

aromatic

${ }^{18}$ F-fluorination

of

4- $\left[{ }^{18}\right.$ F]fluoro- $N$-[2-(1-methoxyphenyl)-1-piperazinyl] ethyl- $N$-2-pyridinyl-benzamide

( $\left.\left[{ }^{18} \mathrm{~F}\right] \mathrm{MPPF}\right)$, which is used as a PET tracer for the evaluation of the $5-\mathrm{HT}_{1 \mathrm{~A}}$ serotonin receptor $^{[19,20]}$, was also investigated using our newly developed microwave system (Table 3). $\left[{ }^{18} \mathrm{~F}\right] \mathrm{MPPF}$ was synthesized via the nucleophilic aromatic substitution reaction which was facilitated by a neighboring nitro group. Because the ${ }^{18} \mathrm{~F}$ anion is only weakly nucleophilic, this reaction usually requires a high temperature and a long reaction time. The conventional heating of 4-nitro- $N$-[2-(1-methoxyphenyl)-1piperazinyl]ethyl- $N$-2-pyridinylbenzamide (nitro-MPPF) in the presence of $\left[{ }^{18} \mathrm{~F}\right] \mathrm{KF}$, Kryptofix2.2.2 and $\mathrm{K}_{2} \mathrm{CO}_{3}$ at $180{ }^{\circ} \mathrm{C}$ for 10 min gave $\left[{ }^{18} \mathrm{~F}\right] \mathrm{MPPF}$ in a $26 \%$ yield (Table 3, entry 1), whereas microwave heating gave the product in $74 \%$ yield (Table 3 , entry 2 ). Raising the temperature of the microwave reaction from room temperature to $180{ }^{\circ} \mathrm{C}$ 
using $50 \mathrm{~W}$ of microwave power required $30 \mathrm{sec}$, and the reaction was maintained at this temperature for $1 \mathrm{~min}$. This result showed that microwave heating provides shorter reaction times and better yields than conventional heating for ${ }^{18} \mathrm{~F}$-fluorination reactions. Furthermore, the use of microwave heating allowed for the formation of the desired product in good yield using half of the original concentration of the precursor (Table 3, entry 3). Microwave heating gave a better yield than conventional heating until the concentration of precursor was decreased by 75\% (Table 3, entry 4). In a similar manner to the results in Table 2, the results in Table 3showed that the concentration of the precursor could be decreased through efficient heating using microwave irradiation.

\section{Table 3}

Finally, we carried out the multistep synthesis of $N$-succinimidyl 4- $\left[{ }^{18} \mathrm{~F}\right]$ fluorobenzoate $\left(\left[{ }^{18} \mathrm{~F}\right] \mathrm{SFB}\right)$, which has been used for the ${ }^{18} \mathrm{~F}$-labeling of bioactive peptides and nucleic acids ${ }^{[21-23]}$ (Scheme 1). The synthesis of $\left[{ }^{18} \mathrm{~F}\right] \mathrm{SFB}$ requires three-steps, including (1) fluorination with $\left[{ }^{18} \mathrm{~F}\right] \mathrm{KF}$ in the presence of Kryptofix2.2.2 and $\mathrm{K}_{2} \mathrm{CO}_{3}$; (2) deprotection with tetrapropylammonium hydroxide (TPAH); and (3) esterification using $N, N, N^{\prime}, N^{\prime}$-tetramethyl-O-(N-succinimidyl)uranium tetrafluoroborate 
(TSTU), and these steps require long reaction times We synthesized $\left[{ }^{18} \mathrm{~F}\right] \mathrm{SFB}$ under microwave heating conditions using our newly developed reactor system. For the ${ }^{18}$ F-fluorination, the reaction had preceded by $32 \%$ after 1 min under conventional heating conditions, whereas microwave heating gave a conversion in excess of $95 \%$ following the same reaction time. This result demonstrated that microwave irradiation is effective for the ${ }^{18}$ F-fluorination of aromatic compounds such as the SFB precursor. Subsequent sequential deprotection and esterification reaction were conducted under microwave heating over 1 min each to give the crude product. Finally, purification by solid-phase extraction afforded $\left[{ }^{18} \mathrm{~F}\right] \mathrm{SFB}$ in a radiochemical yield of $63 \pm 4 \%$ (decay corrected from $\left[{ }^{18} \mathrm{~F}\right] \mathrm{KF}$ ) with a radiochemical purity of greater than $95 \%$ following a total synthesis time of $25 \pm 5 \mathrm{~min}$. This result therefore provides a clear demonstration of the effectiveness of our newly developed microwave reactor for the ${ }^{18}$ F-fluorination of aromatic substrates, with a significantly improved total synthesis of $\left[{ }^{18} \mathrm{~F}\right] \mathrm{SFB}$.

\section{Scheme 1}

\section{Figure 4}




\section{Conclusions}

We have performed a series of basic examinations of our newly developed microwave reactor, which has a resonance-type irradiation mechanism that is different from those used in commercially available microwave reactor systems. The microwave reactor developed in this study contains a solid-state oscillator, which can be used to precisely control the frequency for the generation of the resonant conditions and therefore powerfully irradiate a small amount of solvent $(0.05-0.5 \mathrm{~mL})$ in the resonant cavity. The effectiveness of our newly developed microwave reactor was evaluated in terms of the effectiveness of its heating effect by performing the radiosynthesis of three completely different PET tracers, including (1) $\left[{ }^{18} \mathrm{~F}\right] \mathrm{FES}$, which was used as a model compound to investigate the simple ${ }^{18} \mathrm{~F}$-fluorination for a sulfonate group; (2) $\left[{ }^{18} \mathrm{~F}\right] \mathrm{MPPF}$, which was used as a model compound for the nucleophilic aromatic substitution of $\left[{ }^{18} \mathrm{~F}\right]$ Fluoride using a nitro group; and $(3)\left[{ }^{18} \mathrm{~F}\right] \mathrm{SFB}$, which was used as a model compound for multistep synthesis. Using our newly developed microwave reactor, we successfully improved each one of these reactions in terms of their yield and the time required for their synthesis compared with the same reactions under conventional heating conditions. These results therefore demonstrate that our newly developed microwave reactor could be useful for PET radiosynthesis. 


\section{Acknowledgments}

This work was partly supported by a Grant-in-Aid for Young Scientists (A), a Grant-in-Aid for Challenging Exploratory Research from the Japan Society for the Promotion of Science, and the New Energy and Industrial Technology Development Organization (NEDO).

\section{Experimental}

\section{General considerations}

All of the reagents and solvents used in the current study were purchased from commercial suppliers and used, as received, without further purification. Dimethyl sulfoxide (DMSO), dimethyl formamide (DMF), methanol (MeOH), toluene, tetrahydrofuran (THF) and potassium carbonate $\left(\mathrm{K}_{2} \mathrm{CO}_{3}\right)$ were purchased from Wako Pure Chemical Industries (Tokyo, Japan). Tetrapropylammonium hydroxide (TPAH) and $N, N, N^{\prime}, N^{\prime}$-tetramethyl-O-(N-succinimidyl)uranium tetrafluoroborate (TSTU) were purchased from Sigma Aldrich(St. Louis, MO, USA). Kryptofix2.2.2 ${ }^{\circledR}$ and anhydrous acetonitrile (MeCN) were purchased from Merck (Darmstadt, Germany). The reference standard and precursors of FES, MPPF and SFB were purchased from ABX Advanced Biochemicals (Radeburg, Germany). Accell Plus CM, Light QMA, Light C18 and Plus PS-2 Sep-Pak cartridges were purchased from Waters Corporation (Milford, MA, USA 
and conditioned with ethanol $(10 \mathrm{~mL})$ and sterile water $(10 \mathrm{~mL})$ prior to use. The reaction vessel was purchased from Oofuna, Ltd. (Osaka, Japan). The material of the reaction vessel was borosilicate glass (length: $4.0 \mathrm{~cm}$, diameter: $1.0 \mathrm{~cm}$, maximum volume: $3.0 \mathrm{~mL}$ ). Radio-TLC analysis was performed on silicagel coated aluminium plates (60 $\mathrm{F}_{254}$, Merck), which were developed in ethyl acetate-hexane (1:2 v/v) and scanned with a sensitive quantitative $\gamma$-detecting instrument (miniGITA Star, RAYTEST, Straubenhardt, Germany). LC-20AD (Shimadzu Corporation, Kyoto, Japan) was used for high-performance liquid chromatography (HPLC) with an SPD-20A (Shimadzu) and NDW-351 (Hitachi Aloka Medical, Ltd., Tokyo, Japan) as an ultraviolet detector ( $\rho: 220$ and $254 \mathrm{~nm}$ ) and radioisotope detector, respectively. HPLC solvents were of HPLC grade. (Nacalai tesque Inc., Kyoto, Japan)

\section{Evaluation of the heating effect on various solvents}

The reaction vessel was charged with solvent (i.e., MeCN, DMF, DMSO, MeOH, Toluene or THF), and the solvent was then irradiated using our newly developed microwave reactor at $50 \mathrm{~W}$ (maximum power).

\section{Example of ${ }^{18}$ F-fluorination}

$\left[{ }^{18}\right.$ F]Fluoride was produced by a cyclotron (CYPRIS HM-18, Sumitomo Heavy 
Industries, Tokyo) via an ${ }^{18} \mathrm{O}(\mathrm{p}, \mathrm{n}){ }^{18} \mathrm{~F}$ reaction and passed through a Sep-Pak Light QMA cartridge (Waters Corporation) as an aqueous solution in ${ }^{18} \mathrm{O}$-enriched water. The cartridge was dried with $\mathrm{N}_{2}$ and the ${ }^{18} \mathrm{~F}$ activity was eluted with $1.0 \mathrm{~mL}$ of a Kryptofix2.2.2/ $\mathrm{K}_{2} \mathrm{CO}_{3}$ solution [9.5 mg of Kryptofix2.2.2 and $1.7 \mathrm{mg}$ of $\mathrm{K}_{2} \mathrm{CO}_{3}$ in acetonitrile/water (96/4)]. The solvent was removed by azeotropic dehydration with acetonitrile $(1.0 \mathrm{~mL})$ at $120{ }^{\circ} \mathrm{C}$ under a stream of argon gas at $10 \mathrm{~min}$.

\section{$16 \alpha-\left[{ }^{18}\right.$ F]Fluoroestradiol $\left(\left[{ }^{18}\right.\right.$ F]FES)}

To prepare ${ }^{18}$ F-labeled $\quad\left[{ }^{18} \mathrm{~F}\right] \mathrm{FES}, \quad$ a solution of 3 -O-methoxymethyl-16,17$O$-sulfuryl-16-epistriol in acetonitrile $(0.1 \mathrm{~mL})$ was added to the reaction vessel containing the ${ }^{18} \mathrm{~F}$ activity (37-74 MBq). After microwave heating (temperature control mode) for $1 \mathrm{~min}$ at $100{ }^{\circ} \mathrm{C}$ and cooling for $1 \mathrm{~min}$, $0.6 \mathrm{M}$ hydrochloric acid/90\% acetonitrile $(0.1 \mathrm{~mL})$ was added. The mixture was heated for $1 \mathrm{~min}$ at $100{ }^{\circ} \mathrm{C}$ and cooled for 1 min. Total synthesis time was $20 \pm 2$ min. TLC analysis was carried out with a $\gamma$-radioactivity TLC scanner (miniGITA Star g-radioactivity TLC scanner, RAYTEST, decay corrected from $\left.\left[{ }^{18} \mathrm{~F}\right] \mathrm{KF}\right)$. Data are the mean \pm S.D. $(n=3)$.

\section{4-[ $\left[{ }^{18}\right.$ F]fluoro- $N$-[2-(1-methoxyphenyl)-1-piperazinyl]ethyl- $N$-2-pyridinylbenzamide}




\section{$\left(\left[{ }^{18} \mathrm{~F}\right] \mathrm{MPPF}\right)$}

To prepare ${ }^{18}$ F-labeled 4 - $\left[{ }^{18} \mathrm{~F}\right]$ fluoro- $N$-[2-(1-methoxyphenyl)-1-piperazinyl]ethyl- $N$-2pyridinylbenzamide ([ $\left.\left.{ }^{18} \mathrm{~F}\right] \mathrm{MPPF}\right)$, a solution of 4-nitro- $N$-[2-(1-methoxyphenyl)-1piperazinyl] ethyl- $N$-2-pyridinylbenzamide (nitro-MPPF) in dimethylsulfoxide $(0.1 \mathrm{~mL})$ was added to the reaction vessel containing the ${ }^{18} \mathrm{~F}$ activity (37-74 MBq). After microwave heating (temperature control mode) for $1 \mathrm{~min}$ at $180{ }^{\circ} \mathrm{C}$ and cooling for 1 min, Total synthesis time was $17 \pm 3$ min. TLC analysis was carried out with a $\gamma$-radioactivity TLC scanner (RAYTEST, decay corrected from $\left[{ }^{18} \mathrm{~F}\right] \mathrm{KF}$ ). Data are the mean \pm S.D. $(n=3)$.

\section{$N$-succinimidyl 4- $\left[{ }^{18} \mathrm{~F}\right]$ fluorobenzoate $\left(\left[{ }^{18} \mathrm{~F}\right] \mathrm{SFB}\right)$}

4-(Ethoxycarbonyl)- $N, N, N$-trimethylbenzenaminium trifluoromethanesulfonate in anhydrous acetonitrile $(2.0 \mathrm{mg} / 0.2 \mathrm{~mL})$ was added to the reaction vessel containing the ${ }^{18} \mathrm{~F}$ activity (3.7-7.4 GBq). After heating for $1 \mathrm{~min}$ at $90{ }^{\circ} \mathrm{C}$ under microwave irradiation (temperature control mode) and cooling for $1 \mathrm{~min}$, the ${ }^{18} \mathrm{~F}$-fluorination was analyzed with a $\gamma$-radioactivity TLC scanner (RAYTEST). Tetrapropylammonium hydroxide (10\% in water, $20 \mu \mathrm{L}$ ) was then added to the mixture. The mixture was heated for $1 \mathrm{~min}$ at $120{ }^{\circ} \mathrm{C}$ under microwave irradiation (temperature control mode) and cooled for 1 
min, and $N, N, N^{\prime}, N^{\prime}$-tetramethyl-O-(N-succinimidyl)uranium tetrafluoroborate in anhydrous acetonitrile (15 mg, $0.2 \mathrm{~mL}$ ) was then added. After heating for $1 \mathrm{~min}$ at $90{ }^{\circ} \mathrm{C}$ under microwave irradiation (temperature control mode), the mixture was diluted with 5\% acetic acid and applied to a Sep-Pak Accell Plus CM Cartridge (Waters Corporation). A Sep-Pak PS-2 Plus Cartridge (Waters Corporation) was attached to the Sep-Pak Accell Plus CM Cartridge, and the cartridges were washed with $20 \mathrm{~mL}$ of acetonitrile/water (20/80). After flowing $\mathrm{N}_{2}$ gas for $10 \mathrm{sec}$, the Sep-Pak Accell Plus CM Cartridge was removed. $\left[{ }^{18} \mathrm{~F}\right] \mathrm{SFB}$ was eluted from the Sep-Pak Plus PS-2 Cartridge with $2.0 \mathrm{~mL}$ of acetonitrile. The isolated radiochemical yield was measured with a curiemeter (IGC-7, Hitachi Aloka Medical, Ltd., Tokyo, Japan, decay corrected from $\left.\left[{ }^{18} \mathrm{~F}\right] \mathrm{KF}\right)$ and the radiochemical purity of the labeled compounds was determined by analytical radio-HPLC. Conditions for HPLC were a Cosmosil 5C-18 AR-II, $4.6 \mathrm{~mm} \times$ $150 \mathrm{~mm}$ column (Nacalai tesque Inc.); a mobile phase of acetonitrile (A) with $0.1 \%$ trifluoroacetic acid and water (B) with $0.1 \%$ trifluoroacetic acid; 0-8 minutes: 30\%-60\% A, 8-15 minutes: isocratic 90\% A; and retention time of $4.98 \mathrm{~min}$. Specific radioactivity was $>14 \mathrm{GBq} / \mu \mathrm{mol}$ calculated by HPLC. Total synthesis time was $25 \pm 5$ min. Data are the mean \pm S.D. $(n=3)$.

\section{Figure 5}




\section{Figure}

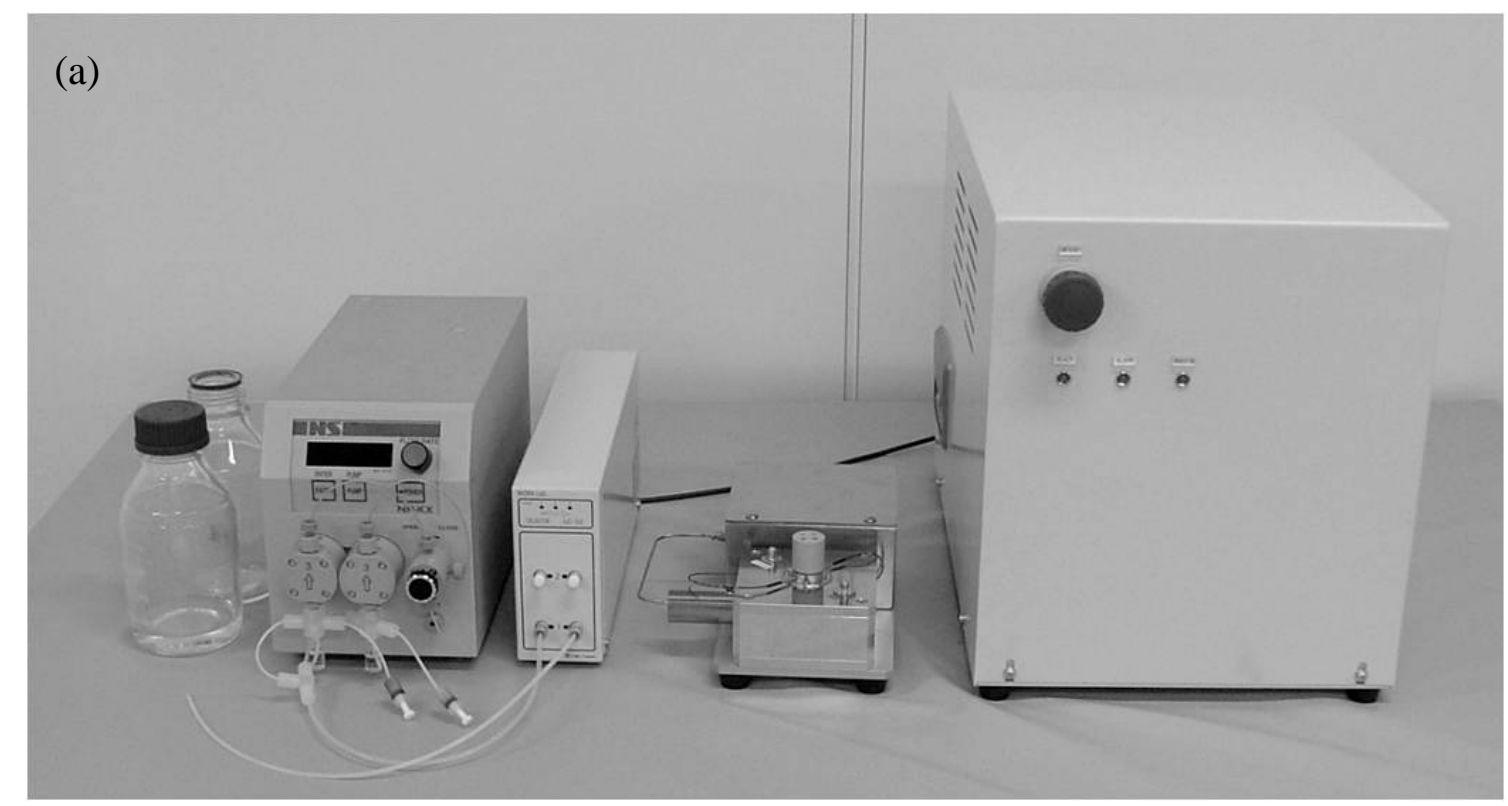

(b)

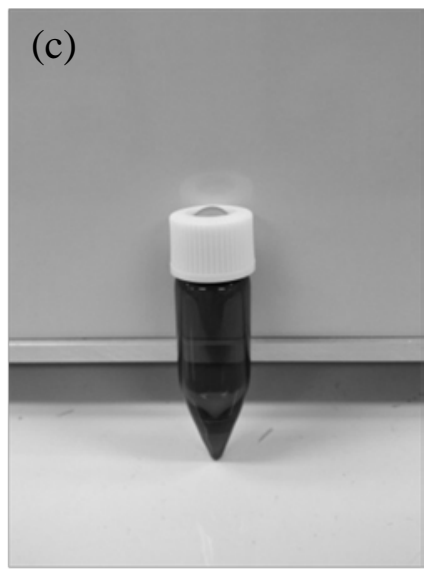

Figure 1. (a) Resonance-type microwave reactor system (Left: liquid delivering unit,

Center: resonant cavity, Right: oscillation unit). (b) Resonant cavity (TM010 single-mode); inner diameter: ø $82 \mathrm{~mm}$, inner height: $30 \mathrm{~mm}$, outer size; depth: $16 \mathrm{~cm}$, width: $23 \mathrm{~cm}$, height: $9 \mathrm{~cm}$. (c) Screw-cap pressure vessel. 


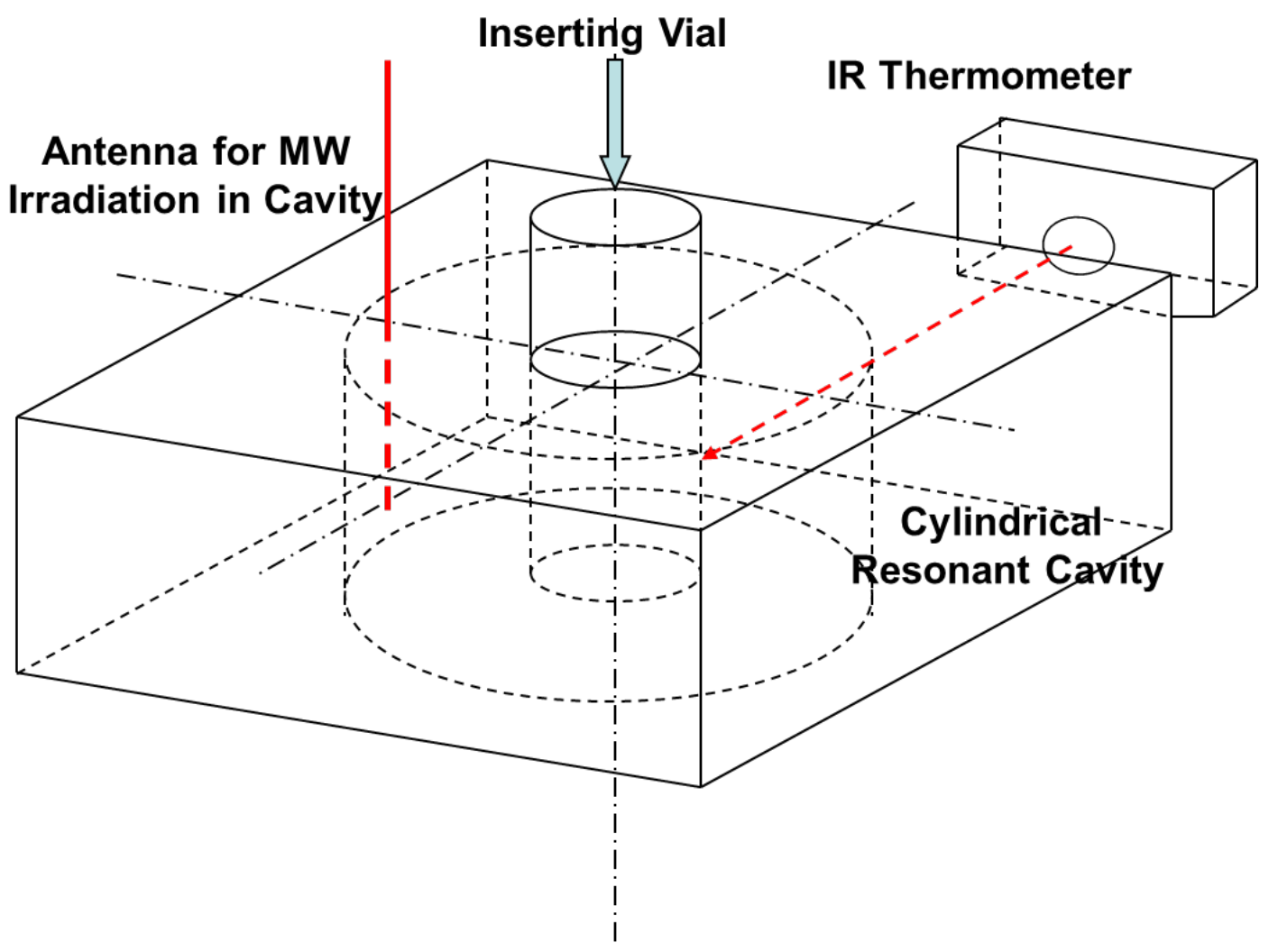

Figure 2. The structure of the microwave irradiation unit. The vial temperature is monitored with an IR thermometer. 


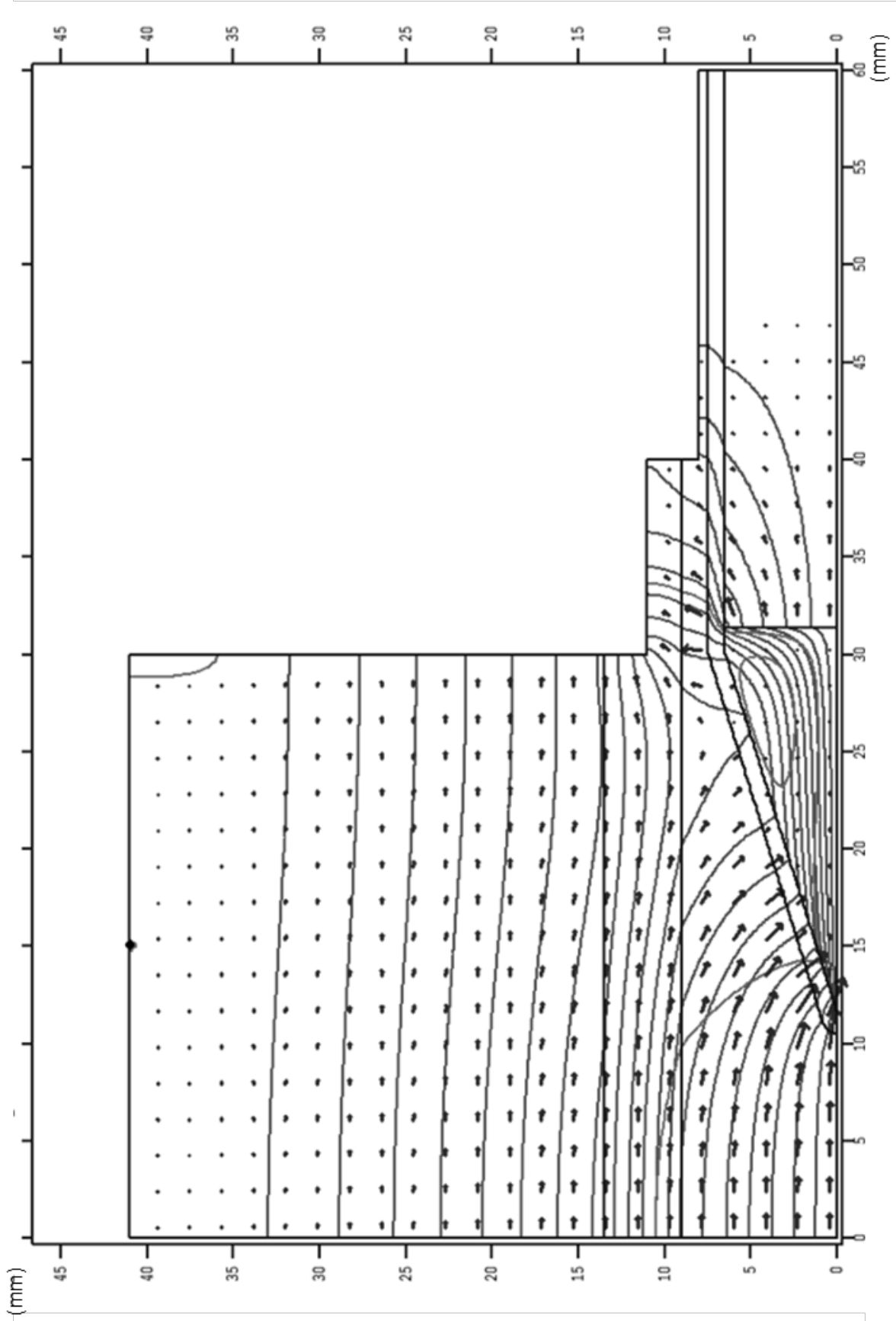

Figure 3. Simulation of the electromagnetic field in the left half of a borosilicate vessel containing $1 \mathrm{~mL}$ of solvent. 


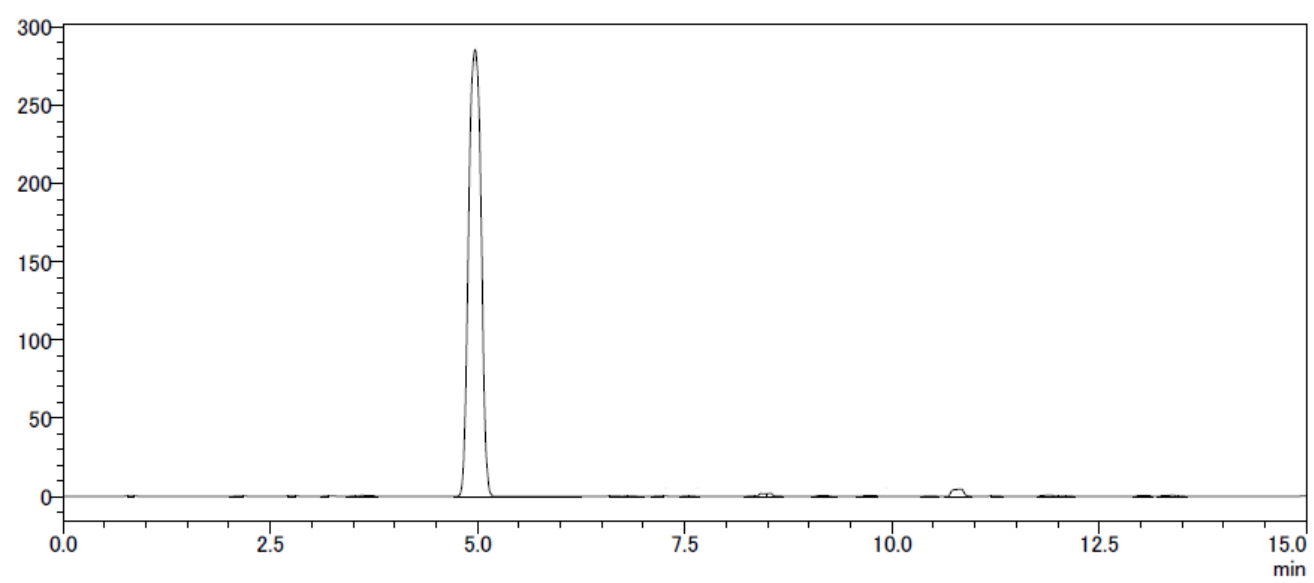

Figure 4. Analytical radio-HPLC chromatogram of purified $\left[{ }^{18} \mathrm{~F}\right] \mathrm{SFB}$ 

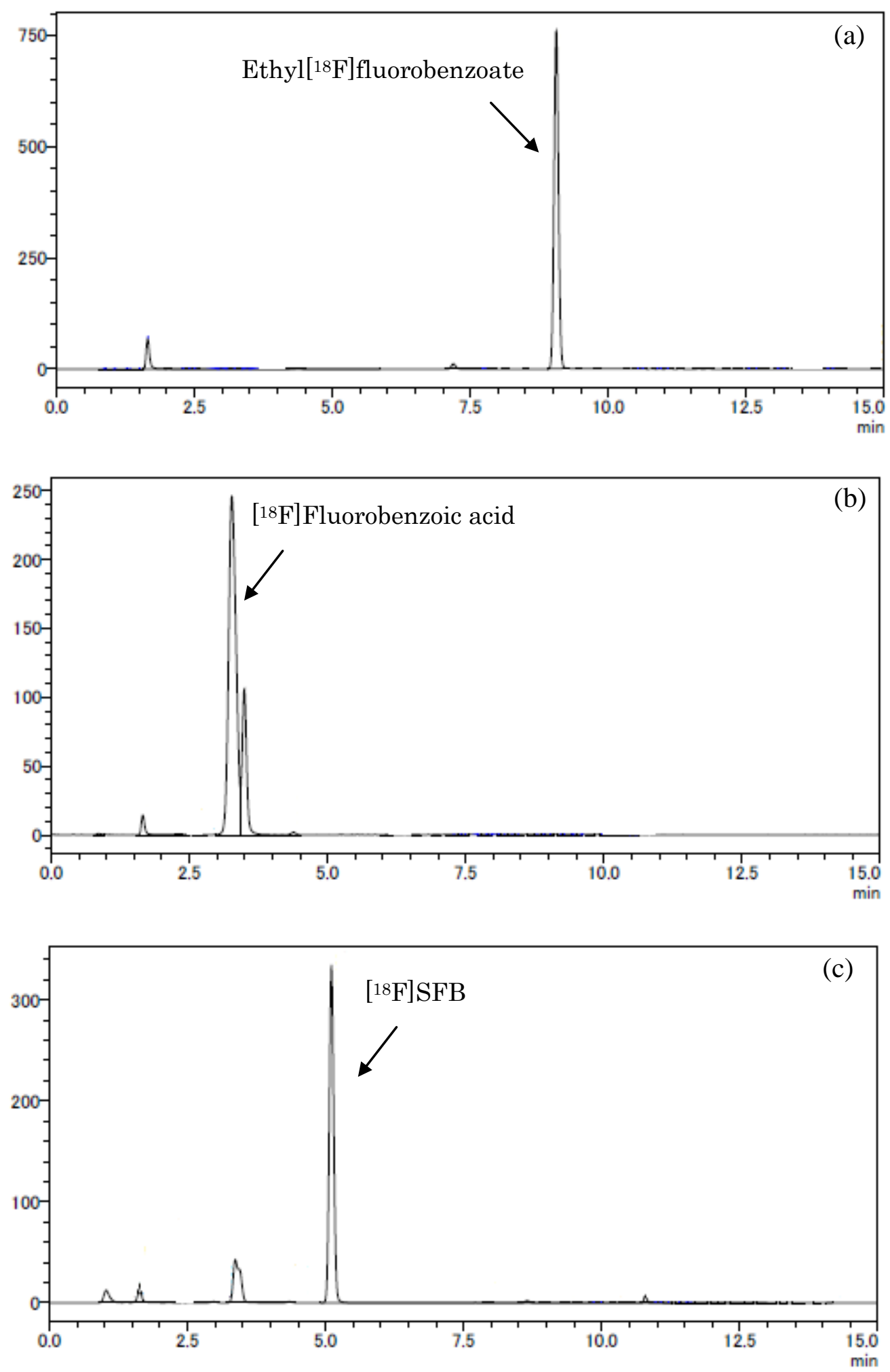

Figure 5. Analytical radio-HPLC chromatogram of crude (a) Ethyl $\left[{ }^{18} \mathrm{~F}\right]$ fluorobenzoate

(b) $\left[{ }^{18}\right.$ F fluorobenzoic acid (c) $\left[{ }^{18} \mathrm{~F}\right] \mathrm{SFB}$ 
Table

Table 1. Evaluation of the heating effect in organic solvents

\begin{tabular}{|c|c|c|}
\hline Solvent & Time to reach temperature (s) & Warming rate $\left({ }^{\circ} \mathrm{C} / \mathrm{s}\right)$ \\
\hline \multicolumn{3}{|l|}{$\mathrm{MeCN}$} \\
\hline $0.2 \mathrm{~mL}, 60^{\circ} \mathrm{C}$ & $8 \pm 1$ & $4.3 \pm 0.3$ \\
\hline $0.2 \mathrm{~mL}, 80^{\circ} \mathrm{C}$ & $12 \pm 0$ & $4.3 \pm 0.1$ \\
\hline $0.1 \mathrm{~mL}, 80^{\circ} \mathrm{C}$ & $13 \pm 1$ & $4.1 \pm 0.2$ \\
\hline $0.05 \mathrm{~mL}, 80^{\circ} \mathrm{C}$ & $12 \pm 1$ & $4.2 \pm 0.1$ \\
\hline \multicolumn{3}{|l|}{ DMF } \\
\hline $0.2 \mathrm{~mL}, 60^{\circ} \mathrm{C}$ & $7 \pm 1$ & $4.8 \pm 0.5$ \\
\hline $0.2 \mathrm{~mL}, 80^{\circ} \mathrm{C}$ & $10 \pm 1$ & $5.6 \pm 0.3$ \\
\hline $0.2 \mathrm{~mL}, 150^{\circ} \mathrm{C}$ & $33 \pm 1$ & $3.6 \pm 0.1$ \\
\hline \multicolumn{3}{|l|}{ DMSO } \\
\hline $0.2 \mathrm{~mL}, 60^{\circ} \mathrm{C}$ & $7 \pm 1$ & $4.7 \pm 0.5$ \\
\hline $0.2 \mathrm{~mL}, 80^{\circ} \mathrm{C}$ & $11 \pm 2$ & $4.9 \pm 0.6$ \\
\hline $0.2 \mathrm{~mL}, 180{ }^{\circ} \mathrm{C}^{*}$ & $35 \pm 2$ & $4.3 \pm 0.1$ \\
\hline \multicolumn{3}{|l|}{$\mathrm{MeOH}$} \\
\hline $0.2 \mathrm{~mL}, 65^{\circ} \mathrm{C}$ & $6 \pm 1$ & $5.8 \pm 0.4$ \\
\hline \multicolumn{3}{|l|}{ Toluene } \\
\hline $0.2 \mathrm{~mL}, 60^{\circ} \mathrm{C}$ & $13 \pm 1$ & $2.7 \pm 0.2$ \\
\hline $0.2 \mathrm{~mL}, 80^{\circ} \mathrm{C}$ & $18 \pm 1$ & $2.9 \pm 0.2$ \\
\hline $0.2 \mathrm{~mL}, 110{ }^{\circ} \mathrm{C}$ & $29 \pm 0$ & $2.8 \pm 0.1$ \\
\hline \multicolumn{3}{|l|}{ THF } \\
\hline $0.2 \mathrm{~mL}, 65^{\circ} \mathrm{C}$ & $11 \pm 2$ & $3.5 \pm 0.3$ \\
\hline
\end{tabular}

*Maximum set temperature of the developed microwave reactor. Data are the mean \pm S.D. $(n=3)$. 
Table 2. Synthesis of $\left[{ }^{18} \mathrm{~F}\right] \mathrm{FES}$ using the developed microwave reactor ${ }^{\mathrm{a}}$

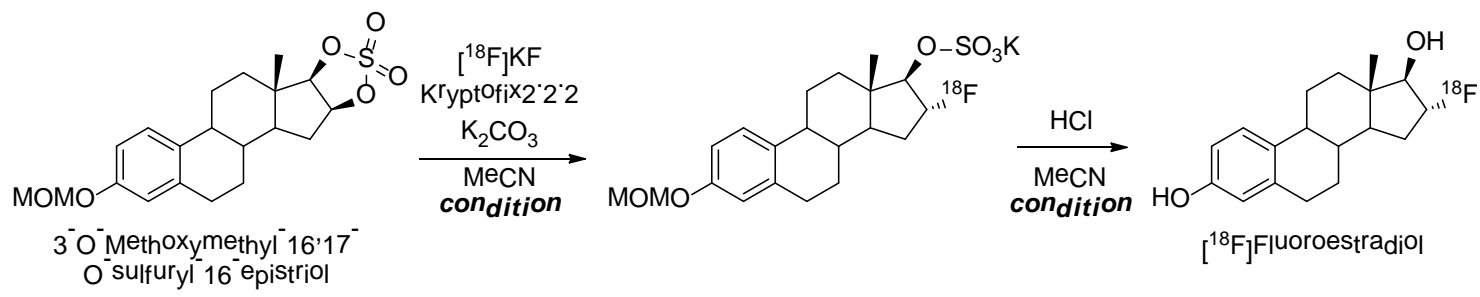

\section{Condition}

Entry Precursor

Microwave

Yield [\% $]^{\mathrm{b}}$

fluorination deprotection

$1 \quad 0.5 \mathrm{mg} \quad 100{ }^{\circ} \mathrm{C}, 10 \mathrm{~min} 100{ }^{\circ} \mathrm{C}, 10 \mathrm{~min} \quad-\quad 68 \pm 2$

$2 \quad 0.5 \mathrm{mg} \quad 100^{\circ} \mathrm{C}, 2 \mathrm{~min} \quad 100^{\circ} \mathrm{C}, 2 \mathrm{~min} \quad-\quad \quad$ No product

$3 \quad 0.5 \mathrm{mg} \quad 100{ }^{\circ} \mathrm{C}, 1 \mathrm{~min} \quad 100{ }^{\circ} \mathrm{C}, 1 \mathrm{~min}+\quad+\quad 89 \pm 2$

$4 \quad 0.25 \mathrm{mg} \quad 100^{\circ} \mathrm{C}, 1 \mathrm{~min} \quad 100^{\circ} \mathrm{C}, 1 \mathrm{~min} \quad+\quad 78 \pm 7$

$5 \quad 0.125 \mathrm{mg} \quad 100{ }^{\circ} \mathrm{C}, 1 \mathrm{~min} \quad 100^{\circ} \mathrm{C}, 1 \mathrm{~min}+70 \pm 9$

${ }^{\mathrm{a}}\left[{ }^{18} \mathrm{~F}\right] \mathrm{KF}: 37$ - $74 \mathrm{MBq}$; MeCN: 0.1 mL; 0.6 M HCl/90\% MeCN: 0.1mL ${ }^{\mathrm{b}}$ Determined from radio-TLC. Data are the mean \pm S.D. $(n=3)$. 
Table 3. Synthesis of $\left[{ }^{18} \mathrm{~F}\right] \mathrm{MPPF}$ using the developed microwave reactor ${ }^{\mathrm{a}}$<smiles>COc1ccccc1N1CCN(CCN(C(=O)c2ccc([N+](=O)[O-])cc2)c2ccccn2)CC1</smiles>

\begin{tabular}{lcccc}
\hline Entry & Precursor & Condition & Microwave & Yield [\% ] \\
\hline $\mathbf{1}$ & $1.500 \mathrm{mg}$ & $180^{\circ} \mathrm{C}, 10 \mathrm{~min}$ & - & $47 \pm 10$ \\
$\mathbf{2}$ & $1.500 \mathrm{mg}$ & $180{ }^{\circ} \mathrm{C}, 1 \mathrm{~min}$ & + & $74 \pm 2$ \\
$\mathbf{3}$ & $0.750 \mathrm{mg}$ & $180^{\circ} \mathrm{C}, 1 \mathrm{~min}$ & + & $56 \pm 8$ \\
$\mathbf{4}$ & $0.375 \mathrm{mg}$ & $180^{\circ} \mathrm{C}, 1 \mathrm{~min}$ & + & $44 \pm 3$ \\
\hline
\end{tabular}

${ }^{\mathrm{a}}\left[{ }^{18} \mathrm{~F}\right] \mathrm{KF}$ : $37-74 \mathrm{MBq}$; DMSO: $0.1 \mathrm{~mL} .{ }^{\mathrm{b}}$ Determined from radio-TLC. Data are the mean \pm S.D. $(n$ $=3)$. 


\section{Scheme}

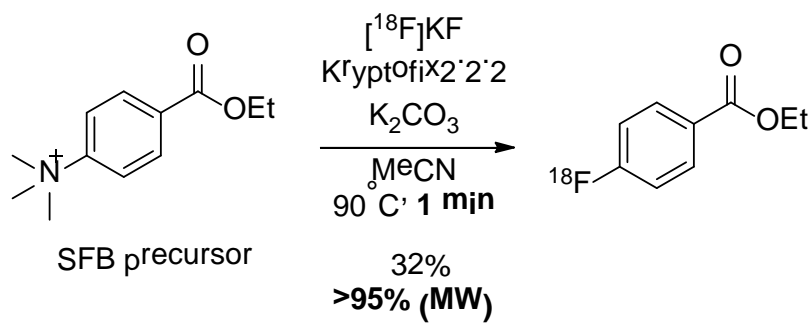
1) TPAH $\mathrm{MeÇN} \mathrm{H}_{2} \mathrm{O}$ $120 \mathrm{C}^{\prime} \mathbf{1} \mathrm{min}$
2) TSTU MeCN 90 C' 1 min<smiles>O=C(ON1C(=O)CCC1=O)c1ccc([18F])cc1</smiles>
(decay corrected from $\left[{ }^{18} \mathrm{~F}\right] \mathrm{KF}$ ) $25 \pm 5$ min (total synthesjs time

Scheme 1. Rapid synthesis of $\left[{ }^{18} \mathrm{~F}\right] \mathrm{SFB}$ using the developed microwave reactor 


\section{References}

[1] R. Gedye, F. Smith, K. Westaway, H. Ali, L. Baldisera, L. Laberge, and J. Rousell, Tetrahedron Lett. 1986; 27, 279-282.

[2] R. J. Giguere, T. L. Bray, S. M. Duncan, and G. Majetich, Tetrahedron Lett. 1986; 27, 4945-4948.

[3] E. Van der Eycken, P. Appukkuttan, W. De Borggraeve, W. Dehaen, D. Dallinger, and C. O. Kappe, J. Org. Chem. 2002; 67, 7904-7907.

[4] Z. Zhao, D. D. Wisnoski, S. E. Wolkenberg, W. H. Leister, Y. Wang, and C. W. Lindsley, Tetrahedron Lett. 2004; 45, 4873-4876.

[5] V. A. Chebanov, V. E. Saraev, S. M. Desenko, V. N. Chernenko, S. V. Shishkina, O. V. Shishkin, K. M. Kobzar, and C. O. Kappe, Org. Lett. 2007; 10, 1691-1694.

[6] C. O. Kappe, Chem. Soc. Rev. 2008; 37, 1127-1139.

[7] A. Sharma, P. Appukkuttan, and E. Van der Eycken, Chem. Commun. 2012; 48, 1623-1637.

[8] H. M. Kingston, and S. J. Haswell, Microwave-enhanced Chemistry, Fundamentals, Sample Preparation and Applications, American Chemical Society, Washington, D.C., 1997.

[9] S. Stone-Elander, and N. Elander, J. Label Compd. Radiopharm. 2002; 45, 715-746. 
[10] M. C. Lasne, C. Perrio, J. Rouden, L. Barré, D. Roeda, F. Dolle, and C. Crouzel, Top. Curr. Chem. 2002, 222, 201-258

[11] L. Cai, S. Lu, and V. W. Pike, Eur. J. Org. Chem. 2008, 2853-2873

[12] P. W. Miller, N. J. Long, R. Vilar, and A. D. Gee, Angew. Chem. Int. Ed. 2008; 47, 8998-9033

[13] A. E. Kallmerten, A. Alexander, K. M. Wager, and G. B. Jones, Curr. Radiopharm. 2011; 4, 343-354.

[14] A. P. Belanger, M. K. Pandey, and T. R. DeGrado, Nucl. Med. Biol. 2011; 38, 435-441.

[15] K. T. J. Loones, B. U. W. Maes, G. Rombouts, S. Hostyn, and G. Diels, Tetrahedron 2005; 61, 10338-10348.

[16] T. Okamoto, M. Yasuda, S. Hoshino, M. Nishioka, Y. Daino, JEMEA 4th Safety and technical Seminar, 2010.

[17] J. Römer, F. Füchtner, J. Steinbach, B. Johannsen, and F. Rossendorf, Nucl. Med. Biol. 1999; 26, 473-479.

[18] J. L. Lim, Lei Zheng, M. S. Berridge, and T. J. Tewson, Nucl. Med. Biol. 1996; 23, 911-915.

[19] D. Le Bars, C. Lemaire, N. Ginovart, A. Plenevaux, J. Aerts, C. Brihaye, W. 
Hassoun, V. Leviel, P. Mekhsian, D. Weissmann, J. F. Pujol, A. Luxen, and D. Comar, Nucl. Med. Biol. 1998; 25, 343-350.

[20] Teija Koivula, Jaana Laine, Tiina Lipponen, Outi Perhola, Eeva-Liisa Kämäräinen, Kim Bergström, and Olof Solin, J. Radioanal. Nucl. Chem. 2010; 286, 841-846.

[21] U. Ackermann, S. D. Yeoh, J. I. Sachinidis, S. S. Poniger, A. M. Scott, and H. J. Tochon-Danguy, J. Label Compd. Radiopharm. 2011; 54, 671-673.

[22] P. J. H. Scott, and X. Shao, J. Label Compd. Radiopharm. 2010; 53, 586-591.

[23] Matthias Glaser, Erik Årstad, Sajinder K. Luthra, and Edward G. Robins, J. Label. Compd. Radiopharm. 2009; 52, 327-330. 